\title{
Effect of Unsaturated Fatty Acid Omega-3 on Some Biochemical Criteria in White New Zealand Rabbits Administrated with Cyclosporine Drug
}

\author{
Murtadha M. Jawad ${ }^{1^{*}}$ \\ ${ }^{1}$ College of Health and Medical Techniques/Al-Furat Al-Awsat Technical University, Al-Kufa, Iraq \\ "e-mail: kuh.dr.mur@atu.edu.iq
}

\begin{abstract}
The present study was aimed efficiency to evaluate the unsaturated fatty acid omega-3 in reducing the side effects that resulted from the administration of cyclosporine drug in white rabbits. (60) white males' rabbits were used in this study, divided into four groups contain (15) rabbits per group and its subdivision into three groups (5) rabbits per group. The first group is orally administered with normal saline, the second group was administered cyclosporine $(25 \mathrm{mg} / \mathrm{kg})$ only. Third groups were administered cyclosporine on the first day and omega-3 $(500 \mathrm{mg} / \mathrm{kg})$ on the second day, while Fourth groups were administered cyclosporine on the first day and omega-3 $(1000 \mathrm{mg} / \mathrm{kg})$ on the second day for periods $(21,30,60)$ days respectively. After ending study periods, the animals were sacrificed and the blood was collected and the results were shown the following: Administration with cyclosporine $(25 \mathrm{mg} / \mathrm{kg})$ only and for periods were led to a significant increase $(P<0.05)$ in total cholesterol, triglycerides and low-density lipoprotein $(L D L)$ and a significant decrease $(P<0.05)$ in high-density lipoprotein $(H D L)$. whereas interaction with $(500 \& 1000 \mathrm{mg} / \mathrm{kg})$ of omega-3 and to all periods showed a significant decrease $(p<0.05)$ in the total cholesterol, triglycerides and low-density lipoprotein $(L D L)$ and significant decrease $(p<0.05)$ in high-density lipoprotein $(H D L)$, while the nonsignificant difference in high-density lipoprotein $(H D L)$. This study concluded that omega-3 has an important role in reducing biochemistry side effects that result from the administration of cyclosporine drugs in white rabbits.
\end{abstract}

Keywords: Cyclosporine, omega-3, High density lipoprotein, Low density lipoprotein

Article Information

Received: January 10, 2021; Revised: : February 27, 2021; Online: March 1, 2021

\section{INTRODUCTION}

The drug makes to suppress the immune system by inhibiting the receptors of T-lymphocytes (sensitivity to the proteins responsible for the stimulus), this effect prevents the binding of cytokines, which are the natural stimuli for the immune response (Borel, 1989).

Cyclosporine targets the $\mathrm{T}$ cells by binding to cytoplasmic receptors in $\mathrm{T}$ cells called (Cyclophilin), the cyclophilin, makes to inhibit a substance called (Calcineurin) responsible for stimulating the nuclear factor to activate lymphocytes to produce cytokines (Crespo-Leiro, 2005). Several studies have indicated that the effect of cyclosporine is through the activation of the enzyme Thyronin Phosphatase as it makes to remove a phosphate group from the cytoplasmic component of the NF-ATc, and thus it is transferred to the nucleus and is called (NF-ATn) and is linked to the Promotor dependent to the responsible gene On the encoding of interleukin-2 (IL-2), which leads to its non-production and non-stimulation of lymphocytes, and as a result the effect on the performance of the function, reproduction and functioning of lymphocytes (Kelly \& Kahan, 2002).

Studies have found that cyclosporine is absorbed incompletely in the small intestine due to the presence of several factors such as the excretion of bile salts, and pathological conditions such as diarrhea, hepatic intestinal circulation disorders, acute and chronic enteritis and intestinal neuropathy (Cantarovich et al., 2004).

The concentration of the cyclosporin in plasma ranges by about (44-33\%), in lymphocytes about (4$9 \%$ ), while in granulocytes it reaches about (5- 
$12 \%$ ), and its percentage in red blood cells ranges (41-58\%). (Diasio and Lobuglio., 1996).

Several researchers have found that cyclosporine is metabolized about $99 \%$ in the liver by an enzyme called Cytochromes P-450 oxidase (CYP3A) (Pichard et al., 1990; Jones et al., 1997). Almost all of the cyclosporine is excreted by hepatic metabolism by two methods: bile and about $6 \%$ in urine, and $1 \%$ of the antagonist is excreted unchanged (without metabolism), i.e. crude during urination and bile (Bistrup et al., 2001).

Cyclosporine is believed to have many side effects, as it increases the risk of cancer and aids in the growth of tumors (Bradley et al., 1994). Omega3 is defined as: a common name for a group of unsaturated fatty acids) where omega- 3 consists of several fatty acids: First: Alpha-Linolenic acid (ALA): which is one of the essential fatty acids of Omega-3, it is supplied with food Due to the body's inability to manufacture it, ALA is important to human health as it suppresses dampens inflammations, and many chronic diseases such as heart diseases, shock and cancer. It combines with cell membranes, stimulates the repair of blood vessels as it transforms into long chains of omega-3 (Pawlosky et al., 2003). Second: Docosahexaenoic acid (DHA): It is one of the groups of omega-3 acids that makes to reduce the percentage of protein synthesis and accumulation in the brain that causes Alzheimer's disease, by reducing the deposition of (beta-amyloid) substance around brain cells (Hong et al., 2003).

Third: Eicosapentanoic acid (EPA): which are found mainly in fish oil, such as mackerel and salmon, and it represents an essential omega-3 part. It has many beneficial applications, as it helps reduce blood pressure and coronary heart disease (Gesch et al., 2002).

In a study conducted, it was found that polyunsaturated fatty acids such as (omega-3) available in food reduce the risk of coronary heart diseases (CHD). If it was found that eating one or two meals of omega-3 rich fish per week is sufficient to provide protection of diseases when compared with people who do not eat fish (KrisEtherton et al., 2001).

\section{MATERIALS AND METHODS Laboratory Animals}

The total number of study animals is (60) White New Zealand rabbit, and from males only, their weights ranged between (1200-1500 grams) and age between (10-12 months), the animals were obtained from the animal house / College of Veterinary Medicine / University Kufa, the study started from $07 / 15 / 2020$ to $15 / 11 / 2020$. The animals were left in the animal house under standard conditions of temperature (13 hours) during the day and (11 hours) at night, and they were fed well throughout the experiment.

\section{Preparation of study materials Preparation of omega-3}

Omega-3 is available at a concentration of $(500 \& 1000 \mathrm{mg} / \mathrm{kg}$ ) in the form of gelatin capsules, obtained from (Novartis Pharma) and given to male rabbits by mouth depending on the weight of the animal daily. (Murtadha M.Jawad ALkhafaji Arshad Noory AL-Dujaily, 2014)

\section{Preparation of cyclosporine drug}

Cyclosporine is available at a concentration of $(25 \mathrm{mg} / \mathrm{kg})$ in the form of gelatin capsules, obtained from (T\&D pharma Gmbh) and administered to male rabbits by mouth depending on the weight of the animal daily.

\section{Animals Sacrificing}

Male rabbits were dissected after anaesthesia with ether on days $(61,31,22)$ for groups orally dosed for periods $(60,30,21)$ days respectively. After that, the ventral lumen was opened, organs (liver and kidney) were removed and weighed with a Sartorius sensitive scale the organs were placed in $(10 \%)$ formalin solution for fixation until tissue sections were made, staining with eosinhematoxylin, and examining under a strong compound microscope (10 X).

\section{Blood Samples}

Blood samples were taken by heart puncture for both the control group and the dosed groups using medical syringes with a capacity of $(5 \mathrm{ml})$. Then, it was centrifuged at a speed (3000 rpm) for a period of (10 minutes), in order to separate the blood serum from its other components. They underwent direct chemical tests, which included: Estimating total cholesterol, triglycerides, high-density lipoprotein concentration (HDL), and low-density lipoproteins in serum (LDL).

\section{Biochemical parameters Measurement}

Estimation of Total serum cholesterol, Triglycerides, high density lipoproteins (HDL) in Serum Archives by the enzymatic method described by Siedel et al. 1981 was used to estimate total serum cholesterol. The optical absorbance was read at a wavelength of (500) nanometers. 
Calculation of low-density lipoproteins

The equation described by Wilson (1998) was used to calculate low-density lipoproteins, and this equation is:

$$
\begin{aligned}
& \text { LDL. Cholestrol }(\mathrm{mg} / \mathrm{dl}) \\
& =\mathrm{T} \text {. Cholestrol }-[(\mathrm{TG} / 5+\mathrm{HDL}]
\end{aligned}
$$

\section{Statistical Analyses}

The statistical analysis was done using the statistical program (SPSS) and the (T-test) and the least significant difference (L.S.D) with a probability level less than (0.05) to determine the level of significance (George, et al., 2003).

\section{RESULTS}

The effect of cyclosporine dose $(25 \mathrm{mg} / \mathrm{kg})$ in rabbits for different periods of time on Total cholesterol and triglycerides (TG).

The dosing duration (60 days) showed the highest significant effect $(\mathrm{P}<0.05)$ on total cholesterol and Triglycerides concentrations in white rabbits compared with the two periods $(30,21$ days), respectively.

Low-density lipoproteins (LDL) and highdensity lipoproteins (HDL).

The results of Table (1) indicate a significant increase $(\mathrm{P}<0.05)$ in the concentration of lowdensity lipoproteins (LDL) for rabbits administration with the drug cyclosporine at a concentration of $(25 \mathrm{mg} / \mathrm{kg})$ and for periods of time (60,30,32 days), as it reached (283.00), (287.50), (288.75) $\mathrm{mg} / \mathrm{dl}$, respectively, compared with the control group (204.50) mg/dl.

It is also evident from the same table that there is a significant decrease $(\mathrm{P}<0.05)$ in the concentration of HDL high-density lipoproteins, reaching (24.60), (23.05), (22.73) $\mathrm{mg} / \mathrm{dl}$ for periods of (60,30,32 days), respectively, compared to with a control group (79.13) $\mathrm{mg} / \mathrm{dl}$.

The results of the table depict the highest significant effect $(\mathrm{P}<0.05)$ for lipoproteins, which was in the duration (60 days) compared to the two periods (30.21 days), respectively.

Table (1) the effect of cyclosporine dosing at a concentration $(25 \mathrm{mg} / \mathrm{kg})$ in white rabbits and for different periods of time on total Cholesterol and triglyceride concentrations (TG) compared to the control group.

\begin{tabular}{llll}
\hline Parameters & & T. Cholesterol mg/dl & TG mg/dl \\
\hline & 21 day & $277.45^{*}$ & $117.88^{*}$ \\
cyclosporine $(25 \mathrm{mg} / \mathrm{kg})$ & 30day & $332.08^{*}$ & $124.75^{*}$ \\
& 60 day & $344.25^{* *}$ & $127.75^{* *}$ \\
Control & & 238.20 & 64.84 \\
L.S.D. (0.05) & 7.519 & 6.118 \\
\hline * Significant difference with control group below likelihood level $(P<0.05)$. ${ }^{* *}$ Significant difference between doses.
\end{tabular}

Table (2) The effect of cyclosporine drug dosing at a concentration $(25 \mathrm{mg} / \mathrm{kg})$ in white rabbits for different periods of time on the concentration of low-density lipoproteins (LDL) and high-density (HDL) compared to the control group.

\begin{tabular}{llll}
\hline Parameters & & HDL $\mathbf{~ m g} / \mathbf{d l}$ & LDL $\mathbf{~ m g} / \mathbf{d l}$ \\
\hline & 21 day & $283.00^{*}$ & $22.73^{*}$ \\
cyclosporine $(25 \mathrm{mg} / \mathrm{kg})$ & 30day & $287.50^{*}$ & $23.05^{*}$ \\
& 60 day & $288.75^{* *}$ & $24.60^{* *}$ \\
Control & & 79.13 & 204.50 \\
L.S.D. $(0.05)$ & & 4.658 & 2.614 \\
\hline
\end{tabular}

* Significant difference with control group below likelihood level $(P<0.05)$. ${ }^{* *}$ Significant difference between doses.

The effect of dosing the egg rabbit drug cyclosporine at a concentration of $(25 \mathrm{mg} / \mathrm{kg})$ in interaction with my concentration (500 and 1000 $\mathrm{mg} / \mathrm{kg}$ ) of omega-3 compared to the drug group only.
Total cholesterol (T.cholesterol) and triglycerides (TG).

Table (4-9) data indicate a significant decrease $(\mathrm{P}<0.05)$ in the concentration of total cholesterol (Total.cholesterol) and triglycerides (Triglycerides), reaching (153.50), (50.83) mg / dl, 
overlapping the concentration of $(500 \mathrm{mg} / \mathrm{kg})$.) For omega-3, (151.63), (44.80) $\mathrm{mg} / \mathrm{dl}$, in interfering with the concentration of $(1000 \mathrm{mg} / \mathrm{kg})$ for omega3 , respectively, compared with the drug group only (315.25), (97.38) $\mathrm{mg} / \mathrm{dl}$, respectively.

The interaction between cyclosporine at a concentration $(25 \mathrm{mg} / \mathrm{kg})$ and a concentration $(1000$ $\mathrm{mg} / \mathrm{kg}$ ) of omega-3 showed the highest significant effect $(\mathrm{P}<0.05)$ on the above lipid content compared to the interaction with a concentration (500 mg/kg) for omega-3.

Low-density lipoproteins (LDL) and highdensity lipoproteins (HDL).

We conclude from Table (3) that there was a significant decrease $(\mathrm{P}<0.05)$ in the concentration of low-density lipoproteins (LDL) after the intervention with a concentration of $(500 \& 1000$ $\mathrm{mg} / \mathrm{kg}$ ) of omega-3 with the drug cyclosporine ( 25 $\mathrm{mg} / \mathrm{kg}$ ), reaching (162.02), (136.82) $\mathrm{mg} / \mathrm{dl}$, respectively, compared with the drug only (288.00) $\mathrm{mg} / \mathrm{dl}$ group.

From the same table, we note the absence of a significant difference $(\mathrm{P}<0.05)$ with respect to the concentration of high-density lipoproteins (HDL) after the intervention between the drug cyclosporine with a concentration (25 mg / $\mathrm{kg}$ ) and my concentration (500 \& $1000 \mathrm{mg} / \mathrm{kg}$ ) for omega-3.

The white rabbit group showed the highest significant effect $(\mathrm{P}<0.05)$ in the concentration of low-density lipoproteins (LDL) with the interaction of the drug cyclosporine with a concentration (25 $\mathrm{mg} / \mathrm{kg}$ ) and a concentration (1000 $\mathrm{mg} / \mathrm{kg})$ for omega-3 compared with the interaction with the concentration $(500 \mathrm{mg} / \mathrm{kg})$ for omega-3.

Table (3) the effect of dosing of cyclosporine drug at concentration $(25 \mathrm{mg} / \mathrm{kg})$ in interaction with $\mathrm{my}$ concentration $(500 \& 1000 \mathrm{mg} / \mathrm{kg})$ of omega-3 in total cholesterol (T.cholesterol) and triglycerides (TG) compared to the drug group only.

\begin{tabular}{llc}
\hline Parameters & T. Cholesterol mg/dl & TG mg/dl \\
\hline Cyclosporine $(25 \mathrm{mg} / \mathrm{kg})$ & 315.25 & 97.38 \\
Cyclosporine $(25 \mathrm{mg} / \mathrm{kg})+$ omega-3 (21 day) & $153.50^{*}$ & $50.83^{*}$ \\
Cyclosporine $(25 \mathrm{mg} / \mathrm{kg})+$ omega-3 (30 day) & $151.63^{* *}$ & $44.80^{* *}$ \\
L.S.D. (0.05) & 10.325 & 5.918 \\
\hline
\end{tabular}

*A significant difference with the drug group only. ${ }^{* *}$ Significant difference between the two concentrations of Omega$3(500 \& 1000 \mathrm{mg} / \mathrm{kg})$

Table (4) the effect of dosing of cyclosporine drug at a concentration of ( $25 \mathrm{mg} / \mathrm{kg})$ in interaction with my concentration $(500 \& 1000 \mathrm{mg} / \mathrm{kg}$ ) of omega-3 compared to the drug group only in the concentration of low-density (LDL) and high-density (HDL) proteins

\begin{tabular}{lll}
\hline Parameters & LDL $\mathbf{~ m g} / \mathbf{d l}$ & HDL $\mathbf{~ m g} / \mathbf{d l}$ \\
\hline Cyclosporine $(25 \mathrm{mg} / \mathrm{kg})$ & $288.00^{*}$ & 23.00 \\
Cyclosporine $(25 \mathrm{mg} / \mathrm{kg})+$ omega-3 (21 day) & $162.02^{*}$ & 23.48 \\
Cyclosporine $(25 \mathrm{mg} / \mathrm{kg})+$ omega-3 (30 day) & $136.82^{* *}$ & 24.40 \\
L.S.D. $(0.05)$ & 19.157 & N. S \\
\hline
\end{tabular}

* A significant difference with the drug group only.

** Significant difference between the two concentrations of Omega-3 (500 \& $1000 \mathrm{mg} / \mathrm{kg})$.

N.S lack of any moral difference.

The effect of durations on dosing of rabbits.

The interaction between cyclosporine and omega-3 drugs compared to drug group only.

Total cholesterol (T.cholesterol) and triglycerides (TG).

The results indicated in Table (4-11) show a significant decrease $(\mathrm{P}<0.05)$ in the concentration of total cholesterol and triglycerides, reaching (210.3), (97.7) for the period (21 days) $\mathrm{mg} / \mathrm{dl}$. And (199.7), (82.8) $\mathrm{mg} / \mathrm{dl}$ for the period (30 days) and (195.1), (77.0) $\mathrm{mg} / \mathrm{dl}$ for the period (60 days), respectively, compared with the drug group only for the periods (60,30,21 days) (277.4) ), (331.9), (344.3) $\mathrm{mg} / \mathrm{dl}$ for total cholesterol (Total.cholesterol) and (118.1), (124.8), (127.8) mg / dl for Triglycerides respectively.

The interaction between cyclosporine and omega-3 drugs for a period of (60 days) showed a significantly higher effect $(\mathrm{P}<0.05)$ in the concentration of both total cholesterol (Total.cholesterol) and triglycerides compared with the two periods (30.21 days), respectively. 
Low-density proteins (LDL) and highdensity lipoproteins (HDL).

Table (4-12) shows that there was a significant decrease $(\mathrm{P}<0.05)$ in the concentration of low-density lipoproteins (LDL) after the intervention and for $(60,30,32$ days) periods of (122.3), (108.1), (100.6) mg/dl. Respectively, compared with the drug group only (277.5), (344.6), (344.3) $\mathrm{mg} / \mathrm{dl}$, and for the periods $(60,30,32$ days) for the same periods.
Also, from the table, it is evident that there were no significant differences $(\mathrm{P}<0.05)$ in the concentration of high-density lipoproteins (HDL) after the intervention and for all periods compared to the drug group only.

The interaction between cyclosporine and omega-3 drugs for a period of (60 days) showed a significantly higher effect $(\mathrm{P}<0.05)$ on the concentration of low lipoproteins (LDL) compared to the two periods (30, 21 days), respectively.

Table (5): The effect of duration (60,30,21 days) on dosing of the rabbit. The interaction between cyclosporine and omega-3 drugs compared with drug group only and for the same duration in total cholesterol concentration (T.cholesterol) and triglycerides (TG).

\begin{tabular}{lll}
\hline Parameters & T. Cholesterol mg/dl & TG mg/dl \\
\hline Cyclosporine (21 day) & 277.4 & 118.1 \\
Cyclosporine+omega-3 (21 day) & $210.3^{*}$ & $97.7^{*}$ \\
Cyclosporine (30 day) & 331.9 & 124.8 \\
Cyclosporine+omega-3 (30 day) & $199.7^{*}$ & $82.8^{*}$ \\
Cyclosporine (60 day) & 344.3 & 127.8 \\
Cyclosporine+omega-3 (60 day) & $195.1^{* *}$ & $77.0^{* *}$ \\
L.S.D. (0.05) & 15.994 & 8.924 \\
\hline
\end{tabular}

* A significant difference with the drug group only.

** Significant difference between the two concentrations of Omega-3 (500 \& $1000 \mathrm{mg} / \mathrm{kg}$ ).

Table (6) the effect of durations $(60,30,21$ days) on dosing of rabbits. The interaction between cyclosporine and omega-3 drugs compared with the drug group only and for the same durations in the concentration of high-density lipoproteins (HDL) and low-density lipoprotein (LDL).

\begin{tabular}{lll}
\hline Parameters & LDL $\mathbf{~ m g / d l}$ & HDL mg/dl \\
\hline Cyclosporine (21 day) & 277.5 & 21.9 \\
Cyclosporine+omega-3 (21 day) & $122.3^{*}$ & 23.5 \\
Cyclosporine (30 day) & 344.6 & 22.8 \\
Cyclosporine+omega-3 (30 day) & $108.1^{*}$ & 22.7 \\
Cyclosporine (60 day) & 344.3 & 23.3 \\
Cyclosporine+omega-3 (60 day) & $127.6^{* *}$ & 24.4 \\
L.S.D. (0.05) & 21.594 & N. S \\
\hline
\end{tabular}

*A significant difference with the drug group only. ** Significant difference between the two concentrations of Omega$3(500 \& 1000 \mathrm{mg} / \mathrm{kg})$. N.S lack of any moral difference.

The effect of interaction between dosing of cyclosporine drug with concentration $(25 \mathrm{mg} / \mathrm{kg})$ and concentration $(500$ and $1000 \mathrm{mg} / \mathrm{kg}$ ) of omega3 in white rabbits for different periods of time compared to the drug group only.

Total cholesterol (T. cholesterol) and triglycerides (TG).

Figure (1), (2) shows a significant decrease (P $<0.05)$ in the concentration of total cholesterol (Total.cholesterol) and triglycerides after the intervention. $500 \& 1000 \mathrm{mg} / \mathrm{kg}$ ) for omega-3 and for all periods of time $(60,30,21$ days $)$ compared to the drug group only.
The interaction with the concentration (1000 $\mathrm{mg} / \mathrm{kg}$ ) of omega-3 and for the period (60 days) showed the highest significant effect $(\mathrm{P}<0.05)$ on the concentration of total cholesterol (Total.cholesterol) and triglycerides compared with the two periods (30.21 days), respectively.

Low-density lipoproteins (LDL) and highdensity lipoproteins (HDL).

Figure (3) underline a significant decrease $(\mathrm{P}$ $<0.05)$ in the concentration of low-density lipoproteins (LDL) after the interaction between cyclosporine and omega-3 at a concentration of $(500 \& 1000 \mathrm{mg} / \mathrm{kg})$ for all periods of time $(60,30,21$ days). Compared with the group of drugs 
only. while The HDL concentration was not affected by the interference.

The interaction with a concentration $(1000 \mathrm{mg} / \mathrm{kg})$ of omega-3 and for a period of (60 days) showed the highest significant effect $(\mathrm{P}<0.05)$ on the concentration of low-density lipoproteins (LDL) compared to the two periods (30.21 days), respectively.

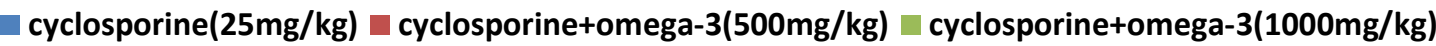

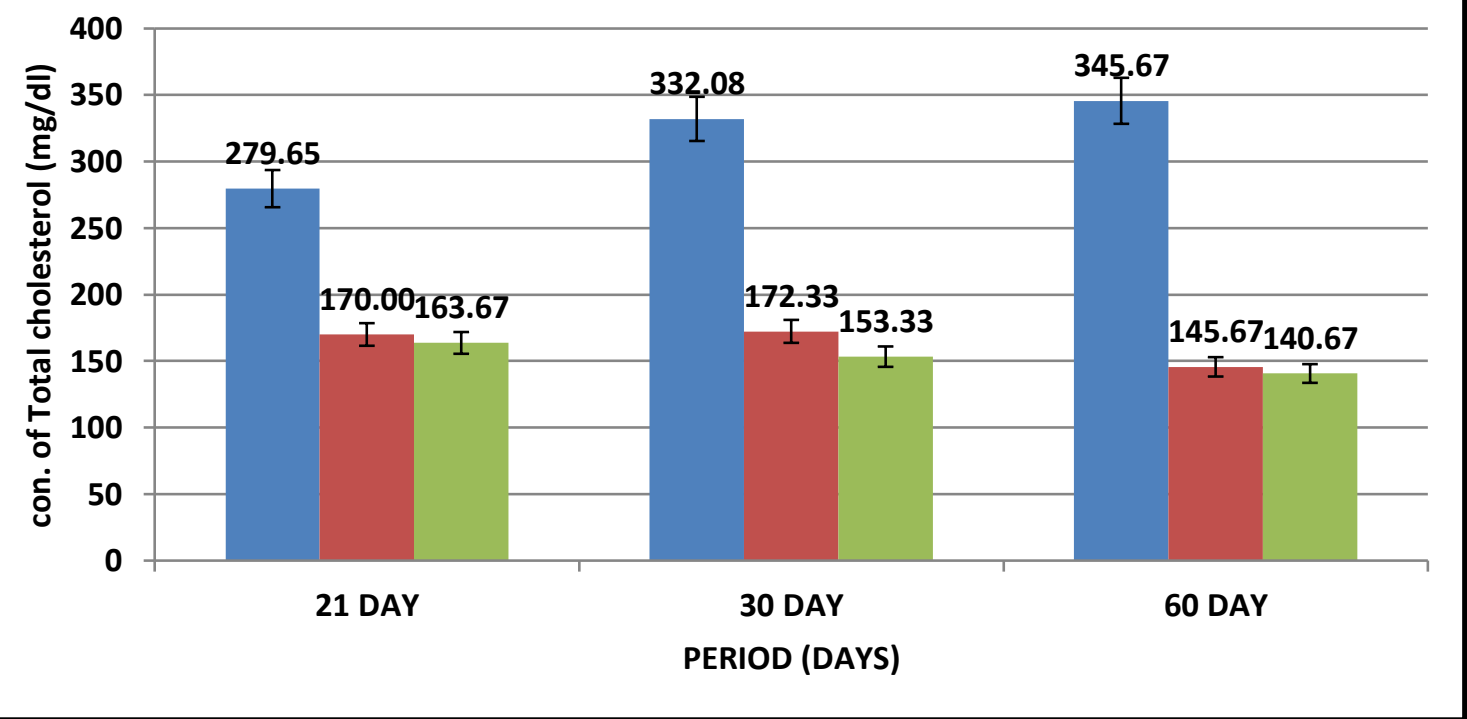

Figure (1) The effect of the interaction between dosing of cyclosporine at a concentration $(25 \mathrm{mg} / \mathrm{kg})$ and a concentration (500 and $1000 \mathrm{mg} / \mathrm{kg}$ ) for omega-3 in egg rabbits and for periods of time $(60,30,21$ days) on the total cholesterol concentration (T.cholesterol). A group compared to the drug group only.

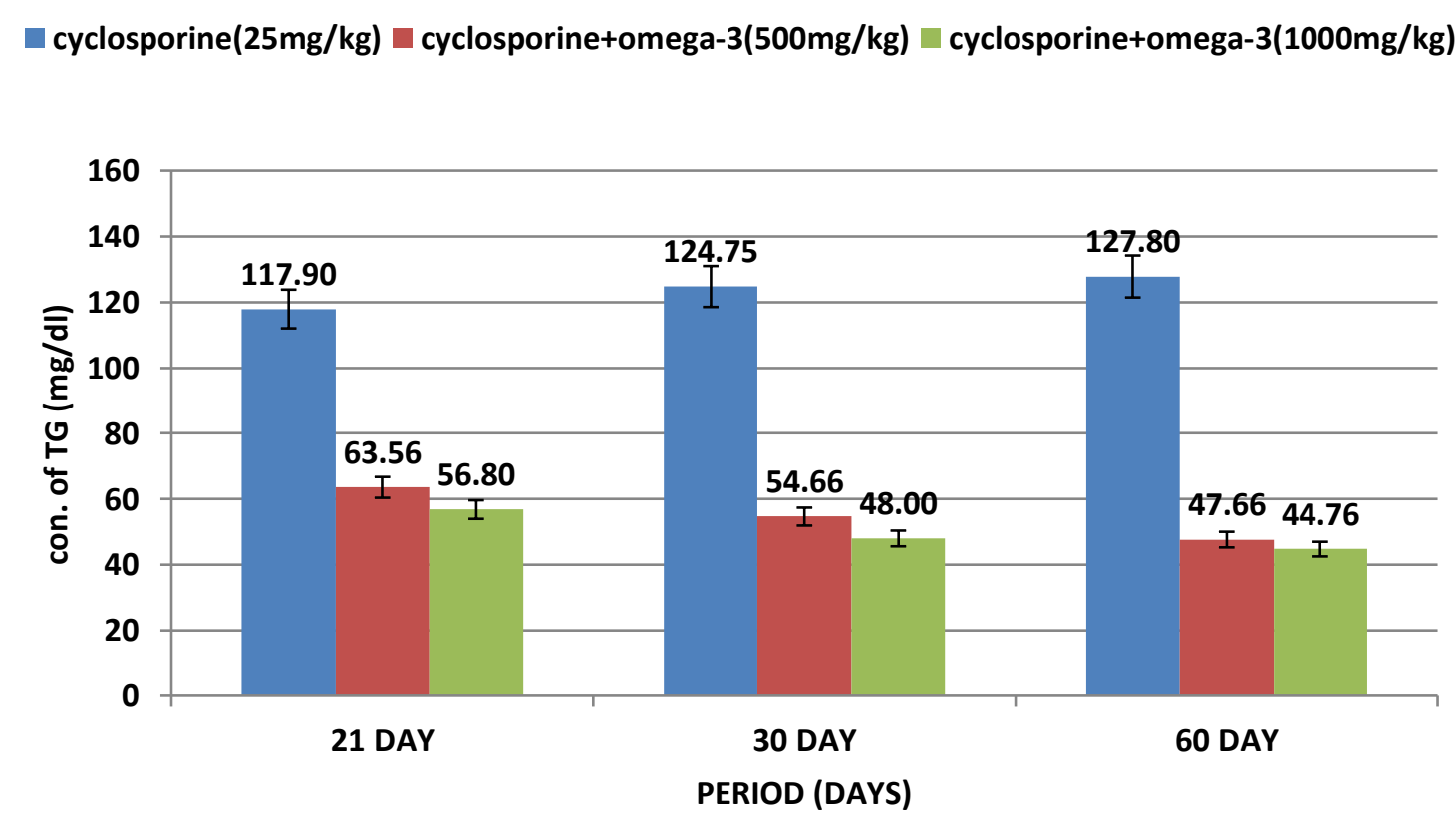

Figure (2) The effect of the interaction between dosing of cyclosporine drug with a concentration (25 $\mathrm{mg} / \mathrm{kg}$ ) and a concentration (500 and $1000 \mathrm{mg} / \mathrm{kg}$ ) for omega-3 in white rabbits and for different periods of time $(60,30,21$ days) in the concentration and triglycerides (TG) Compared with the drug group only. 


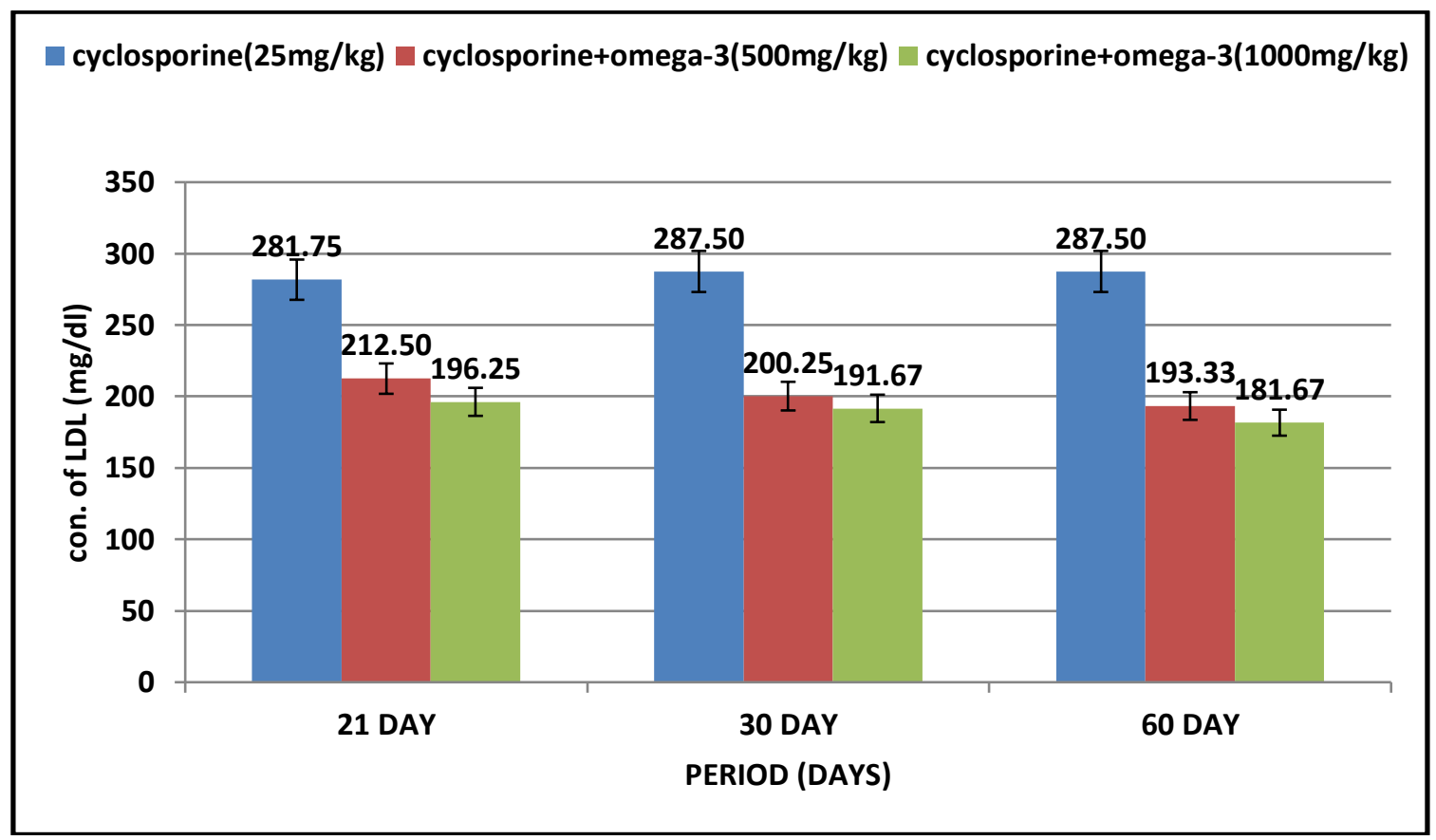

Figure (3) The effect of the interaction between dosing of cyclosporine at a concentration $(25 \mathrm{mg} / \mathrm{kg})$ and a concentration (500 and $1000 \mathrm{mg} / \mathrm{kg}$ ) for omega-3 in white rabbits and for time periods $(60,30,21$ days) on the concentration of low-density lipoproteins (LDL) Compared with a group of drugs only.

\section{DISCUSSION:}

Changes in total cholesterol and triglycerides levels before and after interactions of cyclosporine with omega-3

The current study found a significant increase in the concentration of total cholesterol and triglycerides after treatment with cyclosporine. Many studies found that cyclosporine has a role in increasing the concentration of hypercholesterolemia, which is often associated with a decrease in the level of Lipoprotein A (Markell \& Freidmman, 1989; Holt, 2002; Suleiman etal). , 2009)

Some research has reported that increased cholesterol concentration in kidney transplant patients after treatment with cyclosporine is one of the causes leading to atheroseclerosis and often leads to coronary heart diseases (Kobayashi et al, 1983; John etal, 2000).

Increased cholesterol may be associated with activation of the enzyme Lecithin-cholesterolacyl transferase, which increases inhibition of cholesterol esterification and transfer to the liver and increases its concentration in the blood serum after treatment with cyclosporine (Ballantyn etal, 1989; Moulin etal, 1992).

Edwards et al (2005) study showed that the cause of high cholesterol after treatment with cyclosporine is a decrease in its excretion from biliary excretion.

Other studies have shown that treatment with cyclosporine leads to an increase in the concentration of triglycerides, which is always associated with a decrease in the concentration of HDL / TG, which increases the risk of atherosclerosis (Lukas etal, 1995; Kuster etal, 2004).

The current study found a significant decrease in the total cholesterol and triglyceride concentrations after the omega-3 intervention.

Research has been directed on the use of foods rich in omega-3 because of its association with reducing the risk of cardiovascular disease. Important compounds of omega-3s are the compounds Docosahexanoic (DHA) and Eicosapentaenoic (EPA), which have been considered biomarkers associated with the reduction of cardiovascular disease (Moyad, 2005), Harris and Vouschacky, 2004).

Gebauer etal (2006) stated that eating a meal $(500 \mathrm{mg})$ of EPA and DHA per day is very important in reducing the incidence of atherosclerosis.

A recent study showed that consuming $(700 \mathrm{mg})$ per day of omega-3 gives protection from atherosclerosis because of its relationship with low levels of triglycerides (Mozaffarian, 2007). 
Martin (2003) indicated that the world population groups who eat sea foods have lower incidence of cardiovascular disease. Reports of the World Health Organization WHO (1995) indicated that the death rate among these people is at lower rates compared to others.

The effect of fish oil and omega-3s known as the hypolipidemic effect has great benefit in reducing total cholesterol and triglycerides by reducing the prevention of the release of high-density lipoproteins from the liver or converting carbohydrates into triglycerides and increasing cholesterol excretion through the bile (Mori etal, 2000; Ilamura etal, 2003; Guillote etal, 2010).

The role of omega-3s may also be by increasing the effectiveness of the enzyme lecithin cholesterolacyl transferas.

Changes in the concentration of high and lowdensity lipoproteins before and after the intervention of cyclosporine and omega-3.

The results of the current study indicated a significant increase in the concentration of lowdensity lipoproteins and a decrease in high-density lipoproteins after treatment with cyclosporine.

Cyclosporine may increase the oxidation of lowdensity lipoproteins by increasing their leaching from the arterial walls and their oxidation by combinations of oxygen into oxidized low-density lipoproteins (LDL), which increase the risk of atherosclerosis by increasing the activity of endothelial cells and liberating phospholipids. And thrombus formation (Brown et at. 1993; Edward et al, 2005).

The increase in the concentration of low-density lipoproteins may be associated with the increase in the concentration of cholesterol, and this is what was observed in the current study, as the increase in low-density lipoproteins, which is also called malignancy, is because they transport cholesterol into the bloodstream (Vathsala et al, 1980).

Studies have found that increasing the accumulation of cyclosporine administration, especially in kidney transplant patients for several months, may increase the concentration of low-

\section{REFERENCES}

Ballantyne CM, Podet EJ. Patsch WP. et at (1989).: Effects of cyclosporine therapy on plasma lipoprotein levels. JAMA; 262:53-56.

Bistrup C, Nielsen FT, Jeppesen VE, Dieperink H (2001). Effect of grapefruit juice on Sandimmun Neoral absorption among stable renal allograft recipients.Nephrol Dial Transplant, 16: 373-377. density lipoproteins associated with LDLcholesterol (Hricik et al, 1991; Webb et al, 1993).

The high ratio of LDL-c and HDL-cholesterol to high-density lipoproteins (LDL-c / HDL-c, TG / HDL-c) may be the cause of the decrease in HDL (Ettinger \& Hazzard, 1988).

Some research has indicated an association of high triglycerides with reduced HDLPs by means of neutral lipid exchange (Ballantyne et al, 1989; Webb et al, 1992).

The reason for the high low-density lipoproteins may be due to their increased build-up from the liver as a result of its increased effectiveness, and this is always associated with the increase in cholesterol build-up.

As for the role of omega-3 in reducing the concentration of low-density lipoproteins, some research has indicated the role of omega-3 in preventing fat oxidation, as it has a protective role for these fats (Harris et al, 2009).

A study also showed that omega-3 may reduce the synthesis of low-density lipoproteins by the liver and their elimination by the bile (Hayes, 2000).

Reducing low-density lipoproteins is often associated with lowering the cholesterol concentration, as between Jalcobsen et al (2009), the compounds of EPA and DHA work in a positive manner to reduce both LDL and cholesterol from the liver and reduce its excretion into the bloodstream.

Ramsden et al (2010) study indicated the role of omega-3 in providing protection against cardiovascular disease and myocardial gut, due to its prominent role in lowering the concentration of cholesterol, triglycerides and low-density lipoproteins.

A-Linolenic acid is the main source of omega-3 (EPA, DHA) formation, and its presence in the diet is an important factor in reducing cardiovascular disease (Brouwer et al, 2004).

Bradley, G., and Ling, V (1994). P-glycoprotein, multidrug resistance and tumor progression.Cancer Metastasis Rev., 13: 223-233.

Borel J.F. (1989). The cyclosporins. Transplant. Proc. 21, 810-815.

Brouwer IA, Katan MB, Zock PL (2004). Dietary alphalinolenic acid is associated with reduced risk of 
fatal coronary heart disease, but increased prostate cancer risk: a meta-analysis. J. Nutr., 134, 919-22.

Brown JH, Anwar R, Short CD, et at. (1993).: Serum lipoprotein(a) in renal transplant recipients receiving cyclosponfl monotherapy.Nephrol Dial Transplant;8:863-867.

Crespo-Leiro MG (2005). Calcineurin inhibitors in heart transplantation. Transplantation proceedings; 37(9): Nov.

Cantarovich M, Barkun J, Giannetti N, Cecere R, Besner JG, Tchervenkov J (2004). History of C2 monitoring in heart and liver transplant patients treated with cyclosporine microemulsion.Transplant Proc; $\quad 36(2$ Suppl):442S-447S.

Diasio RB and Lobuglio AF (1996). Immunomodulators: Immunosuppressive agents and immunostimulants, cited in, Goodman \& Gillman's. The pharmacological basis of therapeutics; 9th ed.: 1269 - 1299.

Edwards B.D,Bhatnagar D,Mackness M.L,Gokal R.(2005).Effect of low-dose cyclosporine on plasma loipoproteins and markers of cholestasis inn patients with psoriasis.QIM,88(2):109-113.

Ettinger WH, Hazzard WR. (1988). Prednisone increases very low-density lipoprotein and high-density lipoprotein in healthy men. Metabolism;37: 10551058.

Gesch, C.B., Hammond, S.M., Hampson S.E., Eves, and Crowder M.J. (2002)."Influence of supplementary vitamins, minerals and essential fatty acids on the antisocial behaviour of young adult prisoners. Randomised, placebo-controlled trial". The British Journal of Psychiatry: The Journal of Mental Science 181: 22-8.

Guillote N., Calzada C.,Colas R. and Guichardant M.(2010).Subgram daily supplementation with DHA protects low-density Lipoprotein from Oxidation in healthy men.Atherosclerossis;208:467-472.

Harris WS, Mozaffarian D, Rimm E, Kris-Etherton P, Rudel LL, Appel LJ, Engler MM, Engler MB,Sacks F(2009). Omega-6 fatty acids and risk for cardiovascular disease: a science advisory from the American Heart Association Nutrition Subcommittee of the Council on Nutrition, Physical Activity, and Metabolism; Council on Cardiovascular Nursing; and Council on Epidemiology and Prevention. Circulation.119, 902-7.

Hayes KC. (2000). Dietary fatty acids, cholesterol, and the lipoprotein profile. Br. J. Nutr. 84,397-9.

Holt DW. (2002). Therapeutic drug monitoring of immunosuppressive drugs in kidney transplantation. Curr Opin Nephrol Hypertens;11 (6):65763.
Hong S, Gronert K, Devchand PR, et al (2003). Novel docosatrienes and 17S-resolvins generated from docosahexaenoic acid in murine brain, human blood, and glial cells. Autacoids in antiinflammation.J Biol Chem;278:14677-87.

Hricik DE, Mayes JT, Schulak JA. (1991). Independent effects of cyclosporine and prednisone on posttransplanthypercholesterolemia. Am J Kidney Dis; 18:353-358.

John GT, Dakshinamurthy DS, Jeyaseelan L, Jacob CK. (2000). The effect of cyclosporin A on plasma lipids during the first year after renal transplantation. Jan-Feb;12(1):14-7.

Jones TE, Morris RG, and Mathew TH (1997). Diltiazem-cyclosporine pharmacokinetic interaction-dose-response relationship. Br J Clin Pharmacol.44:499-504.

Kelly P, Kahan BD (2002). Review: metabolism of immunosuppressant drugs.Curr Drug Metab.;3:275-287.

Kris-Etherton, P., Daniels, SR and Eckel,RH.(2001). Summary of the scientific conference on dietary fatty acids and cardiovascular health. Circulation; 103:1034-9.

Kobayashi N, Okubo M, Marumo F, Uchida H, Endo T,Naka.mura H.(1983).Dc novo development of hypercholesterolemia and elevated high-density lipoprotein cholesterol:Apoprotein A-I ratio in patients with chronic renal failure following kidney transplantation.Nephron;35:237-240.

Kuster GM, Drexel H, Blesch JA, et al. (2004). Relation of cyclosporine blood levels to adverse effects on lipoproteins. Transplantation; 57:1479-83.

Lukas B. Hilbrands, Pierre N.M. Demacker, Andries J. Hoitsma, Anton F.H. Stalenhoef, and Robert A.P.Koene.(1995).The Effects of Cyclosporine and Prednisone on Serum Lipid and (Apo)Liproprotein Levels in Renal Transplant Recipients.Department of Medicine, Division of Nephrology, University Hospital Nijmegen, Nijmegen. The Netherlands.J. Am. Soc. Nephrol; 5:2073-2081

Markell MS, Freidman EA (1989). Hyperlipidemia after organ transplantation. Am J Med; 87(5N):61N-7N.

Martin DS. (2003). Dietary protein and hypertension: Where do we stand? Nutrition. 19, 385-6.

Moulin P, Appel GB, Ginsberg HN, Tall AR. (1992). Increased concentration of plasma cholesteryl ester transfer protein in nephrotic syndrome: role in dyslipidemia. J Lipid Res; 33:1817-1822.

Mori T.A., Burke V.,Puddey I.B.,Watts G.F. and Beilin L.J.(2000).Purified EPA and DHA have differential Lipids and Lipoproteins,LDL Particle size, glycoseand insulin in mildly hyperlipidemic men.AM J CLINN Nutr;71:1085-1094. 
Moyad, M. A. (2005). An introduction to dietary/supplemental omega-3 fatty acids for general health and prevention: part I. Urol.Oncol. 23: 28-35.

Mozaffarian D, Micha R, Wallace S. (2010). Effects on coronary heart disease of increasing polyunsaturated fat in place of saturated fat: a systematic review and meta-analysis of randomized controlled trials. PLoS Med.7, 10-252.

Murtadha M.Jawad AL-khafaji Arshad Noory ALDujaily (2014) 'Effect of unsaturated fatty acid Omega-3 on some Hormonal criteria in White rabbits administrated with cyclosporine drug', Magazin of Al-Kufa University for Biology, 6(3), pp. 182-189.

Pawlosky, R., Hibbeln, J., Lin, Y. (2003). n-3 fatty acid metabolism in women. Br.J.Nutr. 90: 993-994.

Pichard L, Fabre I, Fabre G, Domergue J, Saint Aubert B, Mourad G, and Maurel P (1990). Cyclosporin A drug interactions. Screening for inducers and inhibitors of cytochrome P-450 (cyclosporin A oxidase) in primary cultures of human hepatocytes and in liver microsomes.Drug Metab Dispos. 18:595-606.

Ramsden CE, Hibbeln JR, Majchrzak SF, Davis JM. (2010). n-6 Fatty acid-specific and mixed polyunsaturate dietary interventions have different effects on CHD risk: a meta-analysis of randomised controlled trials. Br. J. Nutr.104, 1586-600.

Suleiman B, El Imam M, Elsabigh M, Eltahir K, Eltahir A, Miskeen E. (2009). Lipid profile in post renal transplant patients treated with cyclosporine in Sudan. Saudi J Kidney Dis Transpl; 20:312-7.

Vathsala A, Weinberg RB, Schoenberg L, et al. (1980). Lipid abnormalities in cyclosporine-prednisonetreated renal transplant recipients. Transplantation 1980;48:37-43.

Webb AT, Plant M, Reaveley DA, et at. (1992). Lipid and lipoprotein (a) concentrations in renal transplant patients.Nephrol Dial Transplant;7:636-64 1.

Webb AT, Reaveley DA, O’Donnel M, O'Connor B, Seed M, Brown EA. (1993). Does cyclosporin increase lipoprotein(a) concentrations in renal transplant recipients? Lancet;34 1:268-270. 